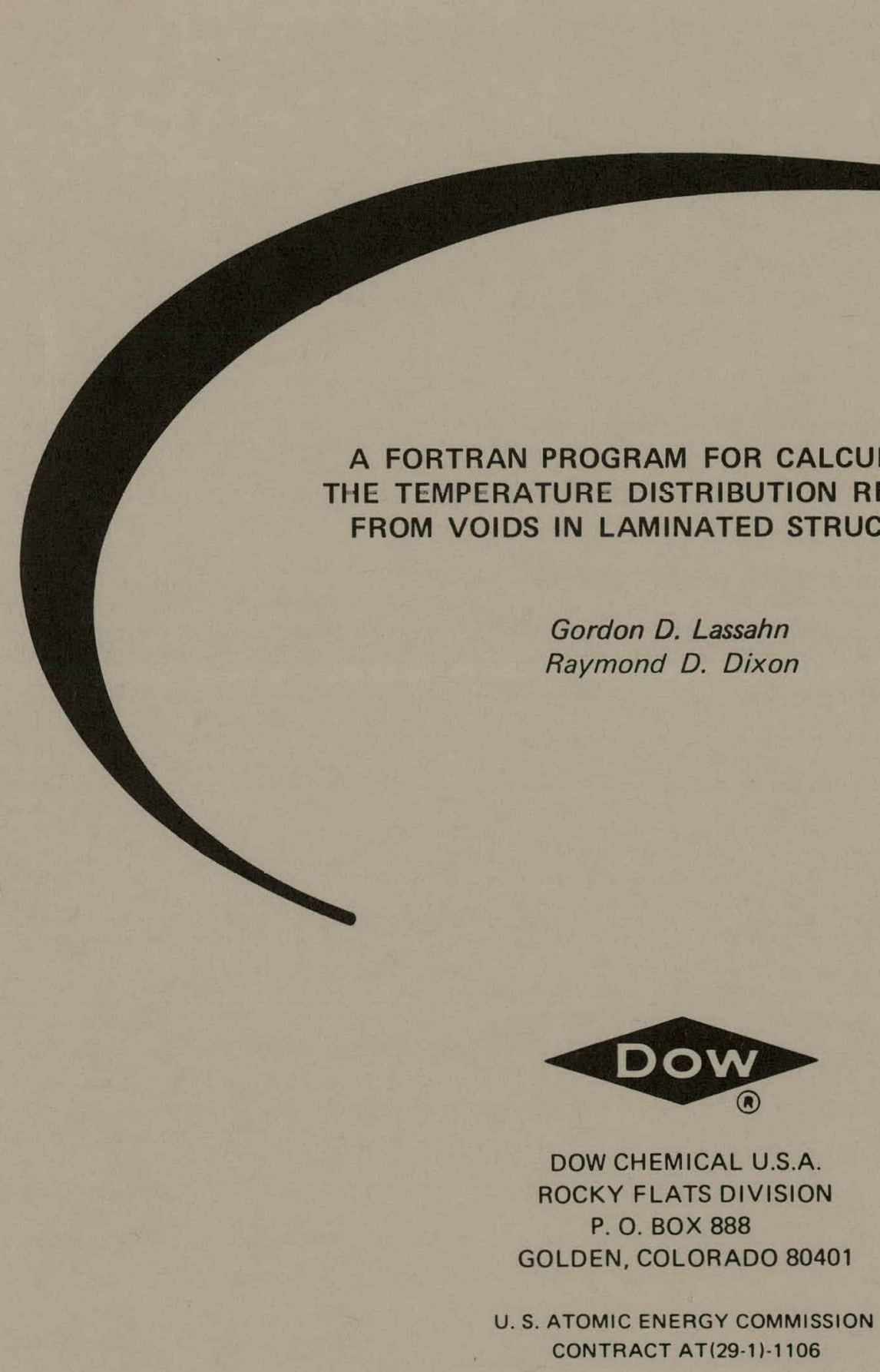

THE TEMPERATURE DISTRIBUTION RESULTING

FROM VOIDS IN LAMINATED STRUCTURES

Gordon D. Lassahn

Raymond D. Dixon

CONTRACT AT(29-1)-1106 


\section{DISCLAIMER}

This report was prepared as an account of work sponsored by an agency of the United States Government. Neither the United States Government nor any agency Thereof, nor any of their employees, makes any warranty, express or implied, or assumes any legal liability or responsibility for the accuracy, completeness, or usefulness of any information, apparatus, product, or process disclosed, or represents that its use would not infringe privately owned rights. Reference herein to any specific commercial product, process, or service by trade name, trademark, manufacturer, or otherwise does not necessarily constitute or imply its endorsement, recommendation, or favoring by the United States Government or any agency thereof. The views and opinions of authors expressed herein do not necessarily state or reflect those of the United States Government or any agency thereof. 


\section{DISCLAIMER}

Portions of this document may be illegible in electronic image products. Images are produced from the best available original document. 


\section{LEGAL NOTICE}

This report was prepared as an account of work sponsored by the United States Government. Neither the United States nor the United States Atomic Energy Commission, nor any of their employees, nor any of their contractors, subcontractors, or their employees, makes any warranty, expressed or implied, or assumes any legal liability or responsibility for the accuracy, completeness or usefulness of any information, apparatus, product or process disclosed, or represents that its use would not infringe privately owned rights.

Printed in the United States of America

Available from the

National Technical Information Service

U. S. Department of Cummerce

Springfield, Virginia 22151

Price: Printed Copy $\$ 3.00$; Microfiche $\$ 0.95$ 
Printed Date

August 10, 1972
RFP-1782

UC-38 ENGINEERING

AND EQUIPMENT

TID-4500 (56th Ed.)

\section{A FORTRAN PROGRAM FOR CALCULATING THE TEMPERATURE DISTRIBUTION RESULTING FROM VOIDS IN LAMINATED STRUCTURES}

Gordon D. Lassahn

Raymond D. Dixon

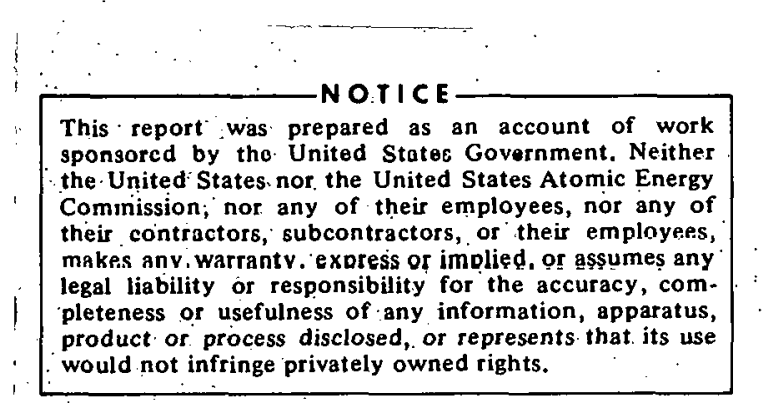

DOW CHEMICAL U.S.A.

ROCKY FLATS DIVISION

P. O. BOX 888

GOLDEN, COLORADO 80401

Prepared under Contract AT(29-1) 1106

for the

Albuquerque Operations Office

U. S. Atomic Energy Commission 
RFP-1782 


\section{CONTENTS}

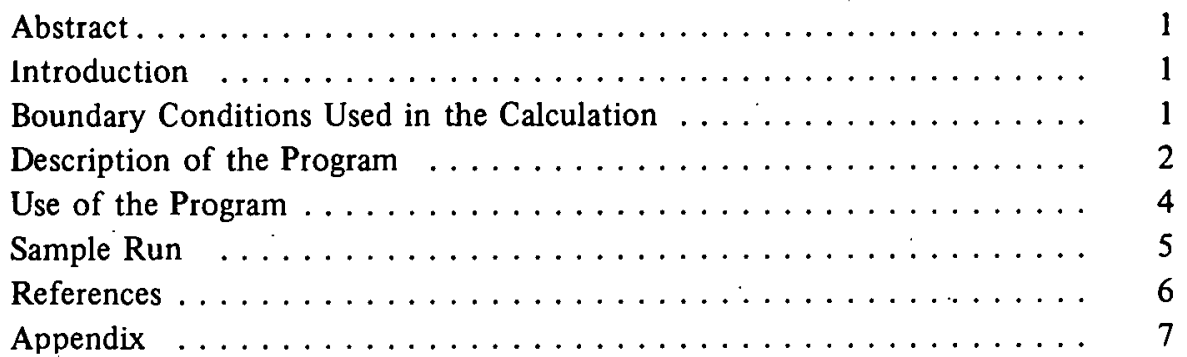


RFP-1782 


\title{
A FORTRAN PROGRAM FOR CALCULATING THE TEMPERATURE DISTRIBUTION RESULTING FROM VOIDS IN LAMINATED STRUCTURES
}

\author{
Gordon D. Lassahn and Raymond D. Dixon
}

\begin{abstract}
Described is a FORTRAN time-sharing program that calculates the steady-state temperature distribution resulting from heat flowing around a void at the interface of a two-layer metal structure. One exterior surface of the structure is heated, and the heat is conducted through the metal plates and across the metal-metal interface to the opposite exterior surface, where the heal is dissipated to the air.
\end{abstract}

The void at the interface is a rectangular cross-section slot in one of the metal plates. The conductivities of the two metals and of the interface, the dimensions of the plates and of the slot, and the boundary temperatures are variable. A sample calculation is presented.

\section{INTRODUCTION}

The computer program described in this report was written in support of a study to determine the feasibility of using infrared thermography to detect bond defects in laminated metal structures. ${ }^{1}$ The program calculates the steady-state temperature distrihution for the model shown in Figure 1. The model consists of a block with a slot across the top (the defect) and a plate on top of the block. The model is heated froin thic bottom with a hot plato, and it dissipates heat into the air from all the other surfaces. The purpose of the calculation was to predict the temperature variation on the top surface of the plate caused by the presence of the slot in the bluck. Adjustable parameters are the sizes of the slot, block, and plate, the hot plate and air temperatures, the plate and block thermal conductivities, and the coefficients for heat transfer across the various surfaces.

\section{BOUNDARY CONDITIONS USED IN THE CALCULATION}

At each interface, i.e., the plate-block interface, the hot plate-block interface, and the block-air and plate-air interfaces, the heat flow is approximated as heing proportional to the temperature difference across the interface:

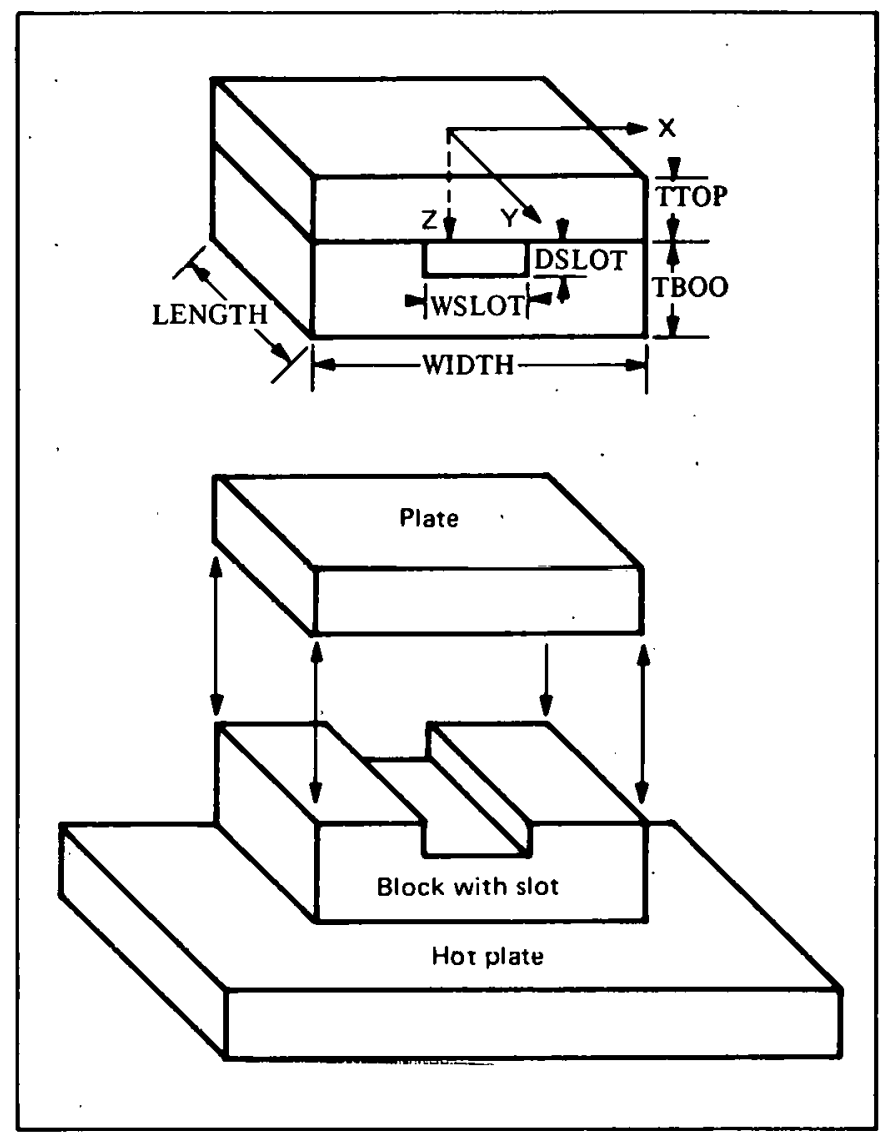

Figure 1. The Model Used for Calculations. Dimensions are labeled with the names of the corresponding computer program input variables.

$\mathrm{J}=\mathrm{C}\left(\mathrm{T}_{1} \cdot \mathrm{T}_{2}\right)$, where

$\mathrm{J}$ is the heat flux from surface 1 to surface 2 (energy $\cdot \operatorname{area}^{-1} \cdot$ time $^{-1}$ ), $\mathrm{C}$ is the thermal conductance per unit area (energy $\cdot$ area $^{-1} \cdot$ time $^{-1} \cdot$ degree $^{-1}$ ), and $T_{1}$ and $T_{2}$ are the temperatures of surfaces 1 and 2 at the interface (degree).

Both the hot plate and the outside air are held at constant temperatures. Heat is conducted directly between the air iit the slot and the outcide air. 


\section{DESCRIPTION OF THE PROGRAM}

For the calculations, a rectangular coordinate system is used. The origin is chosen to be at the center of the top surface of the plate (see Figure 1). The positive Z-axis is normal to the plate and in the direction of the hot plate. The $Y$-axis is parallel to the slot. The X-axis is normal to the slot. The $\mathrm{X} \cdot \mathrm{Z}$ plane and the $\mathrm{Y} \cdot \mathrm{Z}$ plane are symmetry planes, and therefore it is sufficient to calculate the temperature in one-fourth of the assembly, say for $\mathrm{X}>0$ and $\mathrm{Y}>0$.

A three-dimensional rectangular lattice of points is constructed throughout the $\mathrm{X}>0, Y>0$ region. The program adjusts the positions of the interior boundaries (the slot surfaces and the plate-block interface) to coincide with the nearest parallel planar array of points. The single points on these interior boundaries are replaced by pairs of points, one on each side of the boundary. These points are labeled with indexes $I, J$, and $\bar{K}$ for the $Z, X$, and $Y$ directions, respectively. The $\mathrm{K}$ labeling is straightforward, with $\mathrm{K}=1$ at $\mathrm{Y}=0$. Figure 2 shows two sketches of points in a plane parallel to the $\mathrm{X} \cdot \mathrm{Z}$ plane, for the $\mathrm{X}>0$ region. The $I$ and $J$ labelings are indicated in the top and bottom sketches, respectively. The points denoted by triangles are not part of the regular array, but are used as dummy points to simplify the program.

The calculations consist mainly of solving a system of linear equations in which the unknowns are the temperatures of all the points. Of course, there must be as many equations as there are points, and there is a simple correspondence between the equations and the points. The equation for each point states that the net heat flow into the region around that point is zero. This condition follows from the requirement that the temperature of the point be constant in time (that is, the steady state solution is sought), so there can be no change in the heat content of the region around the point.

The (approximate) finite difference equations expressing this condition can be obtained by integrating the (exact) equation of continuity over the region around the point in question, with the time derivative of the temperature not oqual to zoro:

$$
0=\iiint\left(\cdot \rho c / \partial \mathrm{J} / \mathrm{dV}=\iiint \nabla \cdot \mathrm{J} d \mathrm{v}=\oint \mathrm{J} \cdot \mathrm{dA},\right.
$$

where $\rho$ is the density of the material, $\mathrm{c}$ is the specific heat, and $J$ is the heat current. The region of integration is a rectangular solid surrounding the point, as indicated by the dashed lines in Figure 3 for an example point on the surface of the plate.
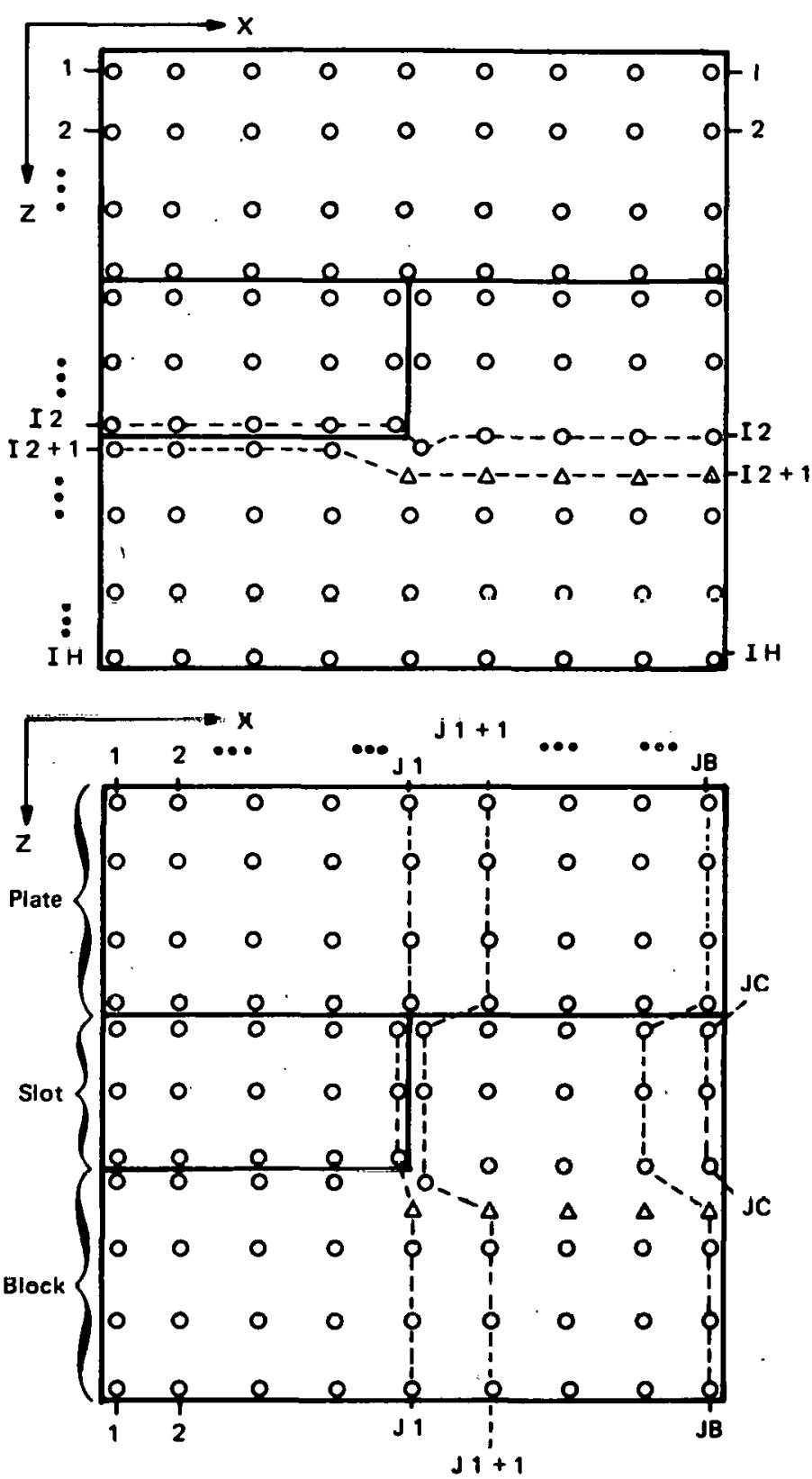

Figure 2. Lobeling of Points in the X-Z Plane.

The surface integral can be written as the sum of six integrals, one for each face of the region of integration. Each of the six integrals can be approximated:

$$
\iint \mathrm{J} \cdot \mathrm{dA}=\mathrm{C}(\mathrm{T} \text { inside }-\mathrm{T} \text { outside }) \mathrm{A}
$$

for a surface at a boundary of the model (the top surface in the example of Figure 3), or

$$
\iint \mathrm{J} \cdot \mathrm{dA}=-\sigma \frac{\partial \mathrm{T}}{\partial \mathrm{n}} \mathrm{A}
$$


for a surface in the interior of one of the parts of the model. Here $\mathrm{n}$ is the coordinate pointing out of the region, perpendicular to the area $A$. The $\partial \mathrm{T} / \partial \mathrm{n}$ is approximated by a finite difference of the form $[T(n+\delta n)-T(n)] / \delta n$, and $A$ is just the area of the surface $(\delta \mathrm{X} \delta \mathrm{Y}$ and $\not 2 \delta \mathrm{X} \delta \mathrm{Z}$ for the top and front surfaces in Figure 3).

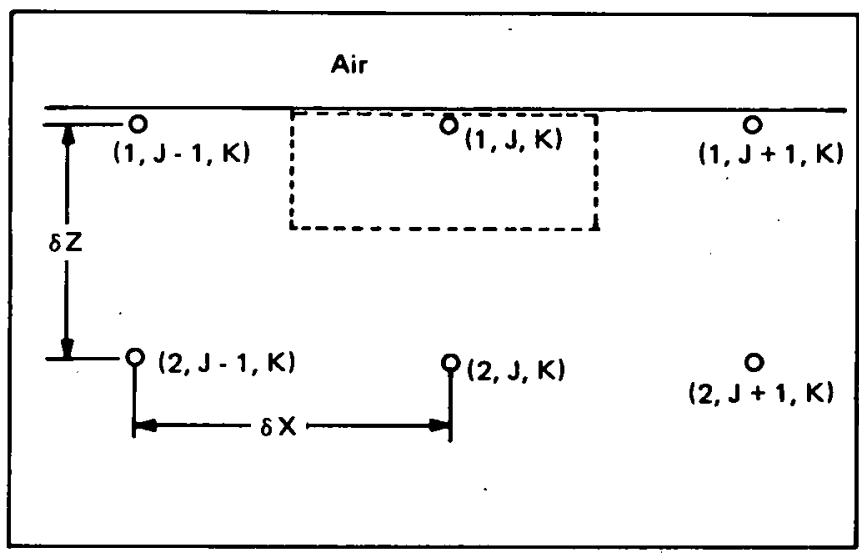

Figure 3. The 1, J, K Point and the Neighboring Points Used in Writing the Temperature Equation for the 1, J, K Point.

The finite difference equation obtained by this scheme for the example point $(1, \mathrm{~J}, \mathrm{~K})$ of Figure 3 is:

$$
\begin{aligned}
0 & =[\mathrm{T}(2, \mathrm{~J}, \mathrm{~K}) \cdot \mathrm{T}(1, \mathrm{~J}, \mathrm{~K})] \quad \sigma \delta \mathrm{X} \delta \mathrm{Y} / \delta \mathrm{Z} \\
& +[\mathrm{T}(1, \mathrm{~J}+1, \mathrm{~K}) \cdot \mathrm{T}(1, \mathrm{~J}, \mathrm{~K})] \sigma \delta \mathrm{Y} 1 / 2 \delta \mathrm{Z} / \delta \mathrm{X} \\
& +[\mathrm{T}(1, \mathrm{~J}-1, \mathrm{~K})-\mathrm{T}(1, \mathrm{~J}, \mathrm{~K})] \quad \sigma \delta \mathrm{Y} 1 / 2 \delta \mathrm{Z} / \delta \mathrm{X} \\
& +[\mathrm{T}(1, \mathrm{~J}, \mathrm{~K}+1)-\mathrm{T}(1, \mathrm{~J}, \mathrm{~K})] \sigma \delta \mathrm{X} / 2 \delta \mathrm{Z} / \delta \mathrm{Y} \\
& +[\mathrm{T}(1, \mathrm{~J}, \mathrm{~K}-1)-\mathrm{T}(1, \mathrm{~J}, \mathrm{~K})] \sigma \delta \mathrm{X} / 2 \delta \mathrm{Z} / \delta \mathrm{Y} \\
& +\left[\mathrm{T}_{\text {air }}-\mathrm{T}(1, \mathrm{~J}, \mathrm{~K})\right] \mathrm{C} \delta \mathrm{X} \delta \mathrm{Y},
\end{aligned}
$$

where $\sigma$ is the conductivity of the plate material, $\mathrm{C}$ is the previously mentioned conductance per area of the plateair interface, $\delta \mathrm{X}, \delta \mathrm{Y}, \delta \mathrm{Z}$ are the dimensions of one cell in the model, and $T_{a i r}$ is the temperature of the surrounding air (a known constant). An equation of this form (simplified by dividing by a factor like $\sigma \delta \mathrm{X} \delta \mathrm{Y} \delta \mathrm{Z} / 2$ ) is used for each point in the model.

This system of linear equations is solved by the GaussSeidel iterative method with over-relaxation. ${ }^{2}$ In this method, the temperature of each point in turn is recalculated in each iteration. The most recent previously calculated (or estimated, on the first iteration) values of the temperatures of that point and its neighboring points are used to calculate the correction to the temperature of the point in question. , The temperature of the $(I, J, K)$ point is corrected by the amount

$$
\begin{aligned}
& \mathrm{R}\left[\mathrm{B}(\mathrm{I}, \mathrm{J}, \mathrm{K})+\underset{\mathrm{I}^{\prime}, \mathrm{J}^{\prime}, \mathrm{K}^{\prime}}{\Sigma} \mathrm{A}\left(\mathrm{I}, \mathrm{J}, \mathrm{K}, \mathrm{I}^{\prime}, \mathrm{J}^{\prime}, \mathrm{K}^{\prime}\right)\right. \\
& \left.\mathrm{T}\left(\mathrm{I}^{\prime}, \mathrm{J}^{\prime}, \mathrm{K}^{\prime}\right) \cdot \mathrm{T}(\mathrm{I}, \mathrm{J}, \mathrm{K})\right]
\end{aligned}
$$

where $R$ is the relaxation factor, the A's are the coefficients of the temperatures of the neighboring points, and $B$ is the constant term in the linear equation. For the previously mentioned example, in which $I=1$, we would have

$$
\begin{aligned}
& \mathrm{B}(1, \mathrm{~J}, \mathrm{~K})=\mathrm{DT}_{\text {air }} 2 \mathrm{C} /(\sigma \delta \mathrm{Z}) \\
& \mathrm{A}(1, \mathrm{~J}, \mathrm{~K}, 2, \mathrm{~J}, \mathrm{~K})=2 \mathrm{D} /(\delta \mathrm{Z})^{2}, \\
& \mathrm{~A}(1, \mathrm{~J}, \mathrm{~K}, 1, \mathrm{~J}+1, \mathrm{~K})=\mathrm{A}(1, \mathrm{~J}, \mathrm{~K}, 1, \mathrm{~J} \cdot 1, \mathrm{~K})= \\
& \mathrm{D} /(\delta \mathrm{X})^{2}, \text { and } \\
& \mathrm{A}(1, \mathrm{~J}, \mathrm{~K}, 1, \mathrm{~J}, \mathrm{~K}+1)=\mathrm{A}(1, \mathrm{~J}, \mathrm{~K}, 1, \mathrm{~J}, \mathrm{~K}-1)= \\
& \mathrm{D} /(\delta \mathrm{Y})^{2}, \text { where } \\
& \mathrm{D}=1 /\left[2 \mathrm{C} /(\sigma \delta \mathrm{Z})+2 /(\delta \mathrm{X})^{2}+2 /(\delta \mathrm{Y})^{2}+2 /(\delta \mathrm{Z})^{2}\right]
\end{aligned}
$$

All other A's in this example are zero.

The iteration process will converge for any value of $\mathbf{R}$ between 1 and 2, but there is an optimum value in this range which will give fastest convergence. This optimum value of $R$ depends on the particular problem being worked, and can not be determined before all the model parameters (size and shape of model, thermal conductivities, etc.) are known. In this program, the value of $R$ is large at the beginning of the iteration procedure and is decreased whenever the sum of all the temperature corrections in one iteration is of the opposite algebraic sign from that of the previous iteration. Intuitively, the large $R$ at the beginning causes rapid convergence of the iteration procedure and overshooting the solution to the equations. When the maximum overshoot is reached, the temperature corrections change sign. At this point, $R$ is reduced to decrease the speed of convergence and the overshoot for the next approach to the solution. In this manner, $R$ is decreased in steps as the iteration procedure continues, but $R$ is never allowed to be less than 1 . The procedure continues in this manner until either the number of iterations reaches the maximum allowed or the sum of the squares of all the temperature corrections in one step of the iteration is below some preselected value. In either case, the temperatures of selected points on the top surface are then printed out, and the iteration procedure is resumed with the value of $R$ fixed at one. Normally, only one more step in the iteration will be done before the sum-of-the-squares criterion causes final termination of the calculation and a final printout of the temperature distribution. However, for some cases the first termination may be due to the limit placed on the number of iterations rather than being caused by the sum of the squares criterion. In any case, as many as five more iterations $(R=1.0)$ can be performed before the calculation terminates. These last 
few iteration steps often complete the convergence of a calculation that had been converging slowly with a larger relaxation factor.

\section{USE OF THE PROGRAM}

Table I defines the input variables needed for the program. The input data are in two parts, read in lines 104 and 116. The program is listed in the Appendix. After the tempera-

Table I. Input Variables

Variable Name

DSLOT Thickness of slot.*

ERMAX Value of the sum of the squares of all the temperature corrections in one iteration, for whtch the calculation is considered converged.

IM, JM, KM Number of cells in the $Z, X$, and $Y$ directions, respectively, into which the $X>0, Y>0$ region is divided.

LENGTH Length of slot.*

NMAX Maximum allowable number of iterations.

RO Initial value of the over-relaxation factor.

Si Thermal conductivity of top plate material.

S2 Thermal conductivity of the block material.

S3 Thermal conductivity of the air in the slot.

S12 Thermal conductance per unit area across the block-plate interface.

S13 Thermal conductance per unit area across the interface between the block and the air in the slot.

S23 Thermal conductance per unit area across the interface between the top plate and the air in the slot.

SAIR Thermal conductance per unit area across the oxterior surfaces that dizsipate heat to tho air.

SMO Thermal conductance per unit area acrose the hot plate-block interface.

TA: Air temperature.

TBOO Thickness of the bottom block.*

TH Hot plate temperature.

TTOP Thlekness uf top plate."

WIDTH Width of block in direction perpendicular to slot."

* See Figure 1.

ture calculations are finished for one set of data, the program returns to line 116 to read new values of only those parameters for the next calculation. The values of the parameters read in line 104 are retained from the previous calculation, and the temperature distribution from the previous calculation is used as the beginning of the next calculation. This feature saves computer time when the variables read in line 116 are frequently changed by small amounts. However, if the value of TTOP, the first variable read in line 116 , is zero or negative, the program returns to line 104 and reads new values for all the input variables in both lines 104 and 116, and sets all the temperatures equal to the hot plate temperature for the beginning of the calculation. If IM, the first variable read in line 104, is zero or negative, the program stops. Therefore, a single blank input record causes the program to start over at the beginning, and two blank records in a row cause the program to stop.

For the program to function correctly, the input data must satisfy the following compatibility requiremento:

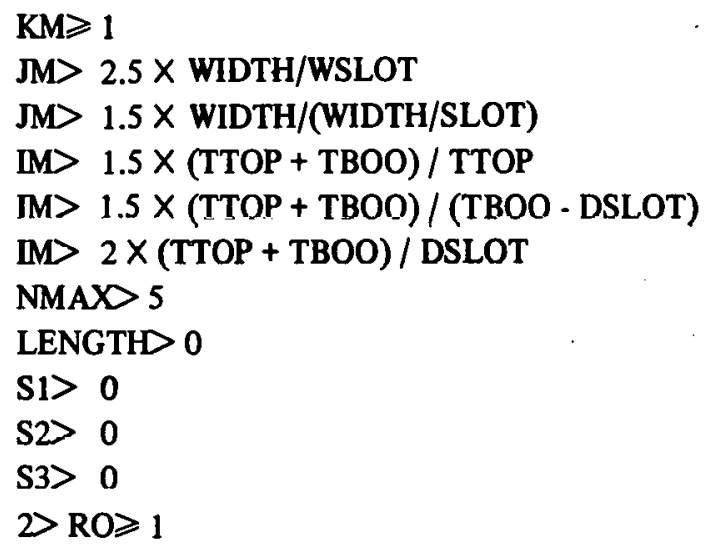

The dimensions of the array $T$, specified in Lines 102 and 342 , must be greater than or equal to (IM +3 , $\mathrm{JM}+2, \mathrm{KM}+1)$.

The input data must be specified in a consistent set of units.

Obviously, one would expect larger values of IM, JM, and KM to give more accurate results, and also to take more computer time and storage space. These factors are best weighed by the user for a particular problem. One aspect to be considered is that if the interior boundaries of the model do not coincide with a plane of points of the array, these model boundaries will be moved by the program, to coincide with the nearest plane of points. Often, IM and $\mathrm{JM}$ can be chosen to make the cell size exactly or nearly commensurate with the specimen dimensions, thus eliminating or minimizing the error caused by moving the interfaces.

For the input parameters used in this work, it was found that convergence was fastest when the value of $\mathrm{RO}$ was about 1.93. It was also found that a highly conductive block-hot plate interface (large SMO) greatly speeded the convergence of the calculation of the temperature distribution without affecting the result of interest (the size of the surface temperature decreased caused by the slot): Using $\mathrm{IM}, \mathrm{JM}, \mathrm{KM}=24,18,8$, with the other parameters approximately equal to those used in the sample run, it was found that NMAX $=400$ was sufficient to allow convergence of most calculations. 
For each iteration, the sum of the squares of all the temperature corrections (SCOR2) is calculated. This is used as an indication of whether the calculation has converged. It is assumed that SCOR2 becomes small when convergence is attained. The examples that were studied verified that the value of SCOR2 does fall off very rapidly at some point in the calculation, and this is assumed to represent convergence. In this program, the iteration procedure stops when SCOR2 is less than the input variable ERMAX.

The best value of ERMAX depends mainly on the number of points, and is limited by the accuracy of the computer. Experience indicates that the maximum value for ERMAX should be about $10^{-7} \times \mathrm{IM} \times \mathrm{JM} \times \mathrm{KM}$. The minimum value should be the product of $\mathrm{IM} \times \mathrm{JM} \times \mathrm{KM}$ multiplied by the square of the smallest non-zero change the computer can make in a temperature value. For example, a sevendigit machine working with temperatures between $20^{\circ}$ and $60^{\circ}$ cannot make a non-zero temperature correction smaller than $10^{-5}$. Then ERMAX should not be smaller than $10^{-10} \times \mathrm{IM} \times \mathrm{JM} \times \mathrm{KM}$.

The output includes a list of the input variable values after the boundary position adjustments have been made, and the temperatures at 50 points on the top surface of the $X>0, Y>0$ portion of the plate. These points are as evenly spaced as possible with five rows in the $Y$ direction and ten rows in the $X$ direction. The $X$ coordinates and the $Y$ coordinates of these points are listed. Also listed are the number of iterations performed, the last value of the relaxation factor used, and the sum of the squares of all the temperature corrections made in the last iteration. These three numbers and the temperature distribution are prin'ted twice for each calculation, as previously described.

If the number of iterations is greater than NMAX-5 for the first listing of the temperatures or greater than 5 for the second listing, the user should assume that convergence has not been attained and that the temperatures indicated might be far from the correct values.

\section{SAMPLE RUN}

This sample run was done on a time-sharing digital computer using a FORTR.AN complier. It is listed in Table II. The parameters were selected to give an example representative of problems with which the authors are experienced, and also to give quick convergence. The parameters are:

plate material: stainless steel, thermal conductivity $=$ 0.14 watt $\cdot \mathrm{cm}^{-1} \cdot{ }^{\circ} \mathrm{K}^{-1}$

plate thickness: $0.159 \mathrm{~cm}$ block material: copper, thermal conductivity: 4.00 watts $\cdot \mathrm{cm}^{-1} \cdot{ }^{\circ} \mathrm{K}^{-1}$

block thickness: $1.27 \mathrm{~cm}$

block width: $6.00 \mathrm{~cm}$

slot depth: $0.635 \mathrm{~cm}$

slot width: $1.27 \mathrm{~cm}$

slot length: $2.54 \mathrm{~cm}$

hot plate temperature: $60^{\circ} \mathrm{C}$

air temperature: $20^{\circ} \mathrm{C}$

Solder between the plate and the block.

Exterior surfaces are painted black; emmissivity is approximately 1 for these surfaces.

Surfaces facing the slot are bare unpolished metal; emmissivity is estimated to be about 0.75 .

Carslaw and $\mathrm{Jaeger}^{3}$ give formulas for the conductance per unit area for the various surfaces. These give:

$$
\begin{aligned}
& \text { SAIR }=0.0008 \text { watt } \cdot \mathrm{cm}^{-2} \cdot{ }^{\circ} \mathrm{K}^{-1} \\
& \text { S13 }=0.0006 \text { watt } \cdot \mathrm{cm}^{-2} \cdot{ }^{\circ} \mathrm{K}^{-1} \\
& \text { S23 }=0.0006 \text { watt } \cdot \mathrm{cm}^{-2} \cdot{ }^{\circ} \mathrm{K}^{-1} \\
& \text { S12 }=8.36 \text { watt } \cdot \mathrm{cm}^{-2} \cdot{ }^{\circ} \mathrm{K}^{-1}
\end{aligned}
$$

The value of SMO should be approximately 0.02 , but the unreasonably high value of 300 watt $\cdot \mathrm{cm}^{-2} \cdot{ }^{\circ} \mathrm{K}^{-1}$ is used to save computer time, as has been mentioned.

The thermal conductivity of air is 0.00023 watt $\cdot \mathrm{cm}^{-1} \cdot{ }^{\circ} \mathrm{K}^{-1}$.

The values $I M=18, J M=15$, and $K M=4$ satisfy the previously mentioned compatibility requirements.

RO is chosen to be 1.93, NMAX is 400, and ERMAX is $10^{-5}$, which is about $10^{-8} \times \mathrm{IM} \times \mathrm{JM} \times \mathrm{KM}$.

These input values. are fed into the computer in the proper order in response the two requests for input at the beginning of the sample run (lines 104 and 116).

In the computer output, WSLOT is listed as 1.200 rather than the input value of 1.27 . This is a result of the shifting of a specimen boundary in the $\mathrm{X}$ direction to make it coincide with the nearest cell boundary. The other boundaries already matched and there was no shifting in the $\mathrm{Z}$ direction.

The output variable SMH is the same as the input variable SMO. Because it was chosen so large, it could not be printed in the specified format.

Since the output indicates that the number of iterations required, 37, was below NMAX-5, 395, and that the sum of the squares of the temperature corrections in the last 
RFP-1782

TABLE II. Sample Run

RUN

$\begin{array}{llll}\text { GDL6 13:31 CSS WED.06/16/71 } & \text { W }\end{array}$

INPUT: 00104

? $18,15,4,20 ., 60 ., 1.27,2.54, .00023,300 ., .0008, .0006, .0006$,

? $1.93,4.00,4.36,400, .00001$

INPUT: 00116

? $.159, .635,1.27,6.0, .14$

TTOP, TBOT, DSLOT, IM, I2, I1 $=\begin{array}{lllllll}0.159 & 1.270 & 0.635 & 18 & 12 & 3\end{array}$

WIDTH, WSLOT, JM, J1, LENGTH, KM $=6.000 \quad 1.200 \quad 15 \quad 4 \quad 2.540 \quad 4$

TA; TH, ERMAX, RO, NMAX = 20. $60 . \quad .0000100 \quad 1.93 \quad 400$

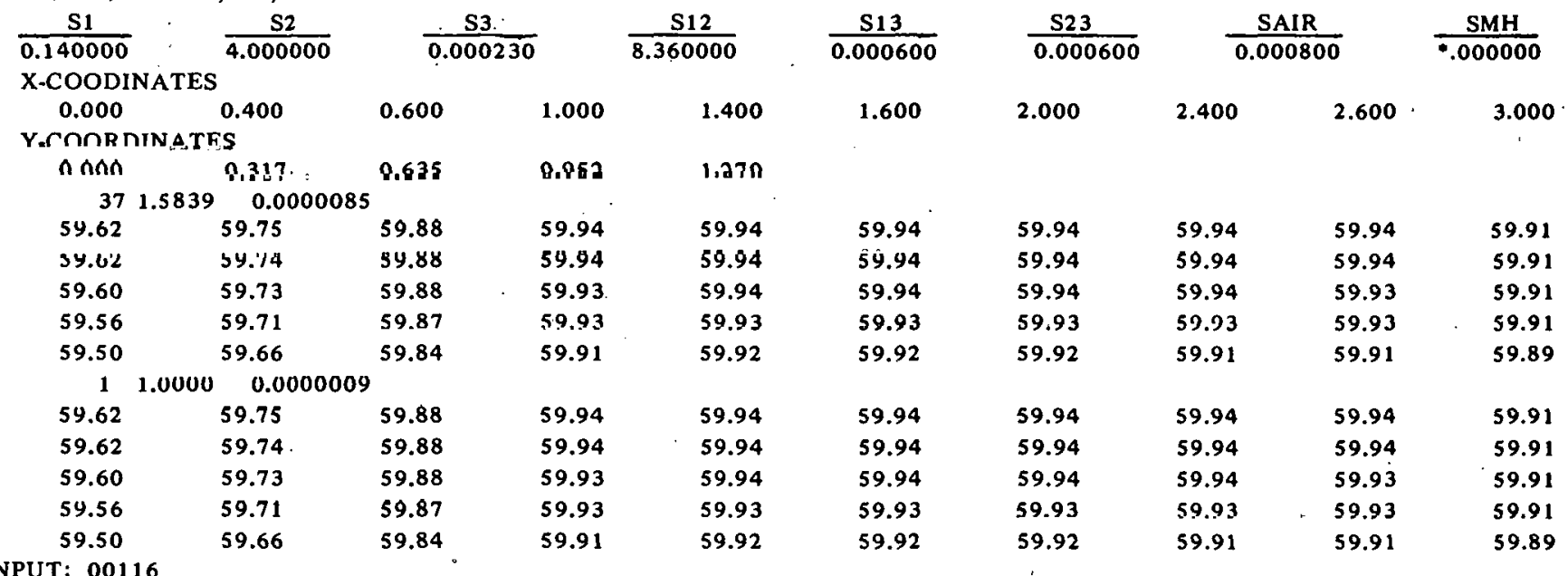

$? 8$

COMPUTER UNITS: 290.4

READY

iteration, 0.0000085 , is below the reasonable value of ERMAX, it can be assumed that the calculation has converged. Further indications of convergence are that only one more iteration was done after the first set and that the temperatures in the two listings agree.

In the array of 50 temperatures listed, the left column of numbers are temperatures of points on the $Y$-axis, and the top row of numbers are temperatures of points on the $X$-axis. Since the width of the slot (WSLOT) is $1.2 \mathrm{~cm}$, the edge of the slot must be at $X=0.6 \mathrm{~cm}$. The list of the $\mathrm{X}$-coordinates indicates that the third column of numbers are temperatures of the surface at $X=0.6 \mathrm{~cm}$, so these points are directly above the edge of the slot.

The temperature above the center of the slot is 59.62 , and the temperature along the $\mathrm{X}$-axis away from the slot is 59.9.4. Therefore, the presence of the slot caused a 0.32 . degree temperature decrease along the $\mathrm{X}$-axis. Along the edge of the top surface, all the temperatures are lower than along the $\mathrm{X}$-axis, and the slot has a greater effect, causing a temperature drop of 0.42 degrees.

After completing the temperature calculation for one set of data, the computer requested a second set of data and the operator terminated execution of the program.

This run required about 12 minutes of terminal time and 39,344 bytes of computer storage space.

\section{REFERENCES}

1. R. D. Dixon, G. D. Lassahn, and A. DiGiallonardo, "Infrared Thermography of Subsurface Defects," Materials Evaluation, Volume $X X X$, No. 4, n 73.

2. Brice Carnahan, H. A. Luther, and James O. Wilkes, A pplied Numerical Methods, (John Wiley and Sons, Inc., New York) 1959, p 508.

3. H. S. Carslaw and J. C. Jaeger, Conduction of Heat in Solids, (Oxford University Press, London) 2nd Edition 1959, p 20. 


\section{APPENDIX}

GDL 6

TUE. $06 / 15 / 71$

$\# \square 1$

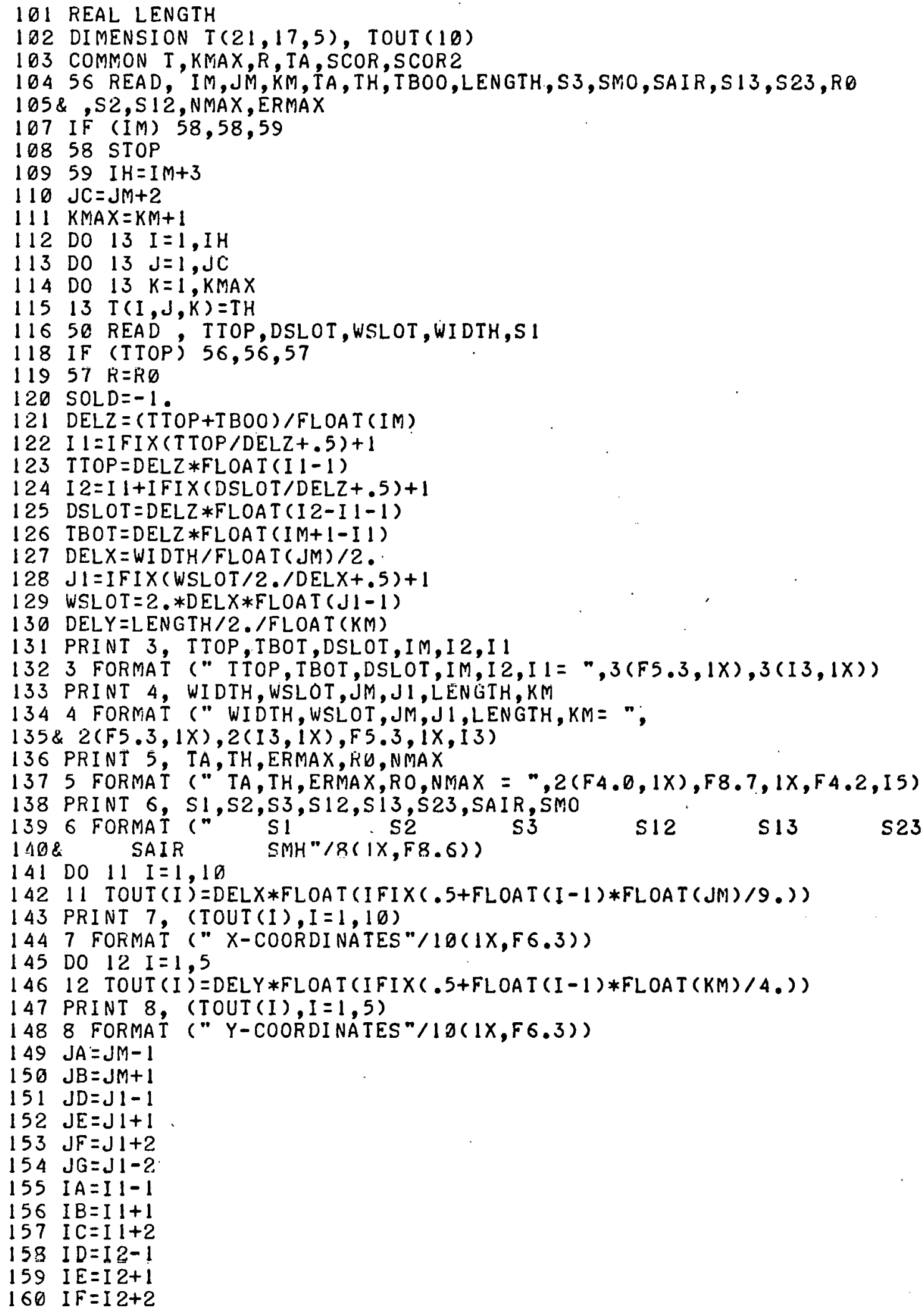


RFP-1782

\section{APPENDIX}

GDL 6

TUE.06/15/71 \#02

$1611 \mathrm{G}=\mathrm{IM}+2$

$162 X=1$. /DEL $X * * 2$

$163 Y=1 . / D E L Y * * 2$

$164 Z=1 . / D E L Z * * 2$

$165 \times 2=2 * * X$

166 Y $2=2, * Y$

$16732-3 .+Z$

168 S I ZZ $=2$.*S 12/SI/DELZ

169 S $13 Z=2 . * S 13 / S 1 / D E L Z$

$170 S 21 Z=2 . * S 12 / S 2 / D E L Z$

$171 \mathrm{~S} 23 \mathrm{Z}=2 . * 523 / \mathrm{S} 2 / \mathrm{DELZ}$

172 S23X $=2$.*S23/S2/DELX

173 S31Z $12 *$. $13 / S 3 / D E L Z$

$174 \mathrm{~S} 32 Z=2 . * S 23 / S 3 / D E L Z$

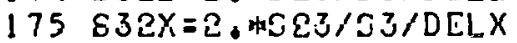

$176 \mathrm{SMH}=2$.*SMO/S2/DELZ

177 SX1=2,*SAIR/S1/DELX

178 SX?.ミ?.*AATR/S?/DELX

179 SY $1=2$.*SAIR/S 1/DELY

180 SY $2=2$.*SAIR/S2/DELY

$181 S Z 1=2$. *SAIR/S I DELZ

$182 \mathrm{D} 1=513 \mathrm{Z} / 2$.

183 D2 $=512 Z / 2$.

$184 \mathrm{~B} 1=(\mathrm{S} 23 \mathrm{X}+\mathrm{S} 23 \mathrm{Z}) / 2$.

185 I KON $=1$

186 MLIM $=$ NMAX- 5

18791 DO $51 M=1$, MLIM

188 SCOR $=\varnothing$.

189 SCOR $\varepsilon=0$.

$190 \quad$ CALL RUNK $(1,1,2,22,2,1, \times 2,1,2,0,0,0,0,0,0,0,0,0$,

$191 \& 1, S Z 1, T A, \emptyset \ldots, \emptyset,, Y, Y Z, S Y I)$

192 DO $21 \mathrm{~J}=2, \mathrm{JM}$

$193 \mathrm{JU}=\mathrm{J}+1$

$194 \mathrm{JV}=\mathrm{J}-1$

19521 CALL RUNK $(1, J, 3, Z 2,2, J, X, 1, J U, X, 1, J V, 0,0,0,0,0,0$,

$196 \& 1, S Z 1, T A, \emptyset \ldots, 0,, Y, Y ?, S Y 1)$

197 CALL RUNK $(1, J B, 2, Z 2,2, J B, X 2,1, J M, 0,0,0,0,0,0,0,0,0$,

$198 \& 2, S Z 1, T A, S X 1, T A, Y, Y 2, S Y 1)$

199 DO 31 I $=2, I A$

?.ด $111=1+1$

201 IV $=I-1$

202 CALL RUNK (I, $1,3, Z, I U, 1, Z, I V, 1, X 2, I, 2,0,0,0,0,0,0$,

$203 \& 0,0,0,0,0,, Y, Y 2, S Y 1)$

204 DO $22 \mathrm{~J}=2, \mathrm{JM}$

$205 \mathrm{JU}=\mathrm{J}+1$

$206 \mathrm{JV}=\mathrm{J}-1$

20722 CALL RUNK (I,J,4,Z,IU,J,Z,IV,J,X,I,JU,X,I,JV, $, ., 0, \emptyset$,

$208 \& 0,0,0,0,0,0,, Y, Y 2, S Y Y 1)$

20931 CALL RUNK (I ,JB, $3, X 2, I, J M, Z, I U, J B, Z, I V, J B, \theta, 0, \theta, \theta ., \theta, \theta$,

$210 \& 1, S X 1, T A, 0,0,0, Y, Y 2, S Y 1)$

211 CALL RUNK (I I, $1,3, S 13 Z, I B, 1, Z 2, I A, 1, X 2, I 1,2,0,0,0,0,0,0$,

$212 \& 0,0,0,0,0,0, Y, Y 2, S Y 1)$

213 DO $23 \mathrm{~J}=2, \mathrm{JD}$

$214 \mathrm{JU}=\mathrm{J}+1$

$215 \mathrm{JV}=\mathrm{J}-1$

21623 CALL RUNK (I I,J,4,Z2, IA, J,S13Z,IB,J,X,I I,JU,X, I I,JV, $, ., 0,0$,

$217 \& 0,0,0 ., 0,0,, Y, Y 2, S Y .1)$

218 CALL RUNK (I 1,J1,5,Z2,IA,J1,X,I1,JD,X,I I,JE,D I, IB, JI., D2, IB, JE, 
RFP-1782

\section{APPENDIX}

GDL 6

TUE. $06 / 15 / 71 \quad \# 03$

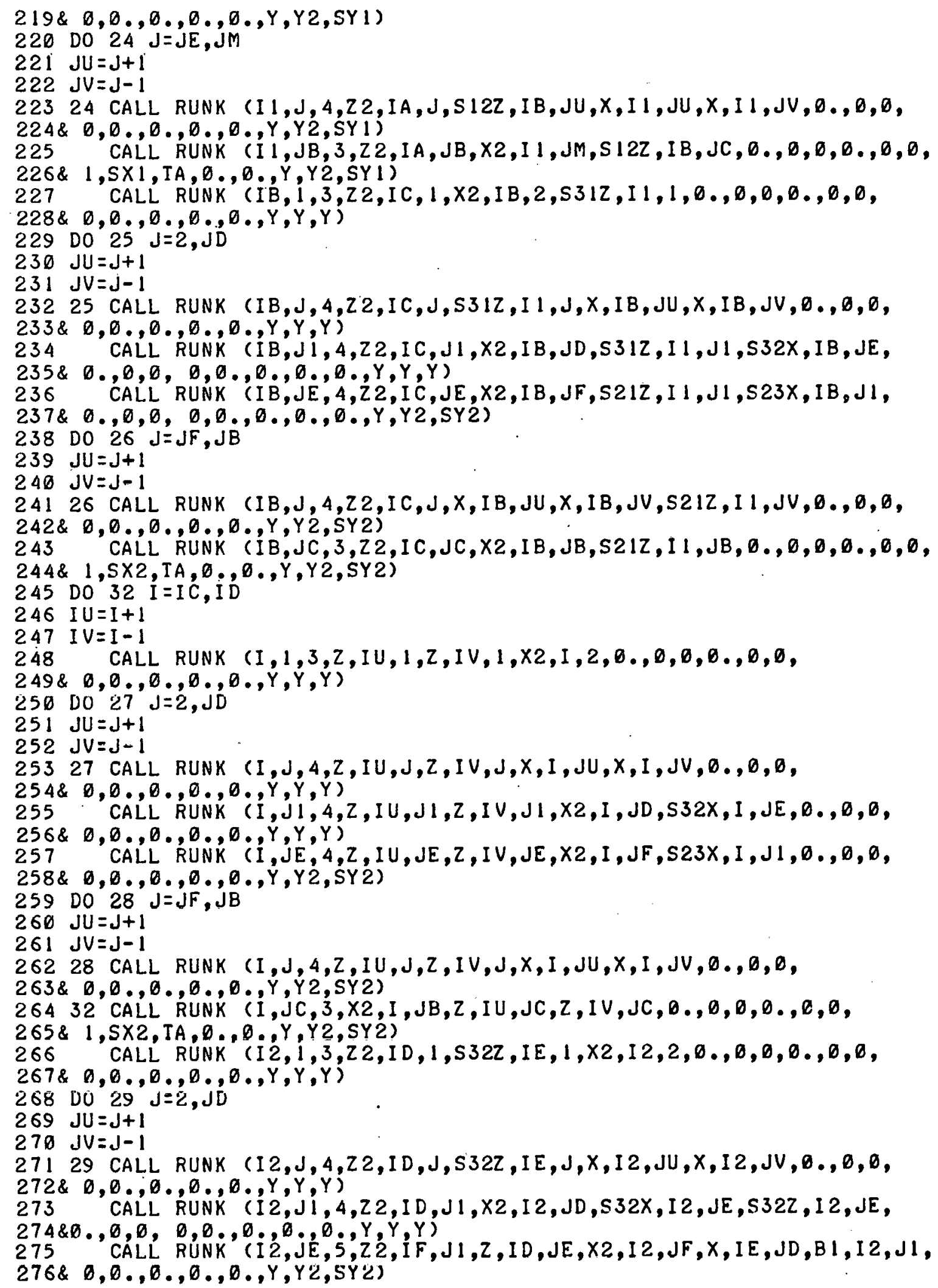


RFP-1782

\section{APPENDIX}

GDL6 TUE.06/15/71 \#ø4

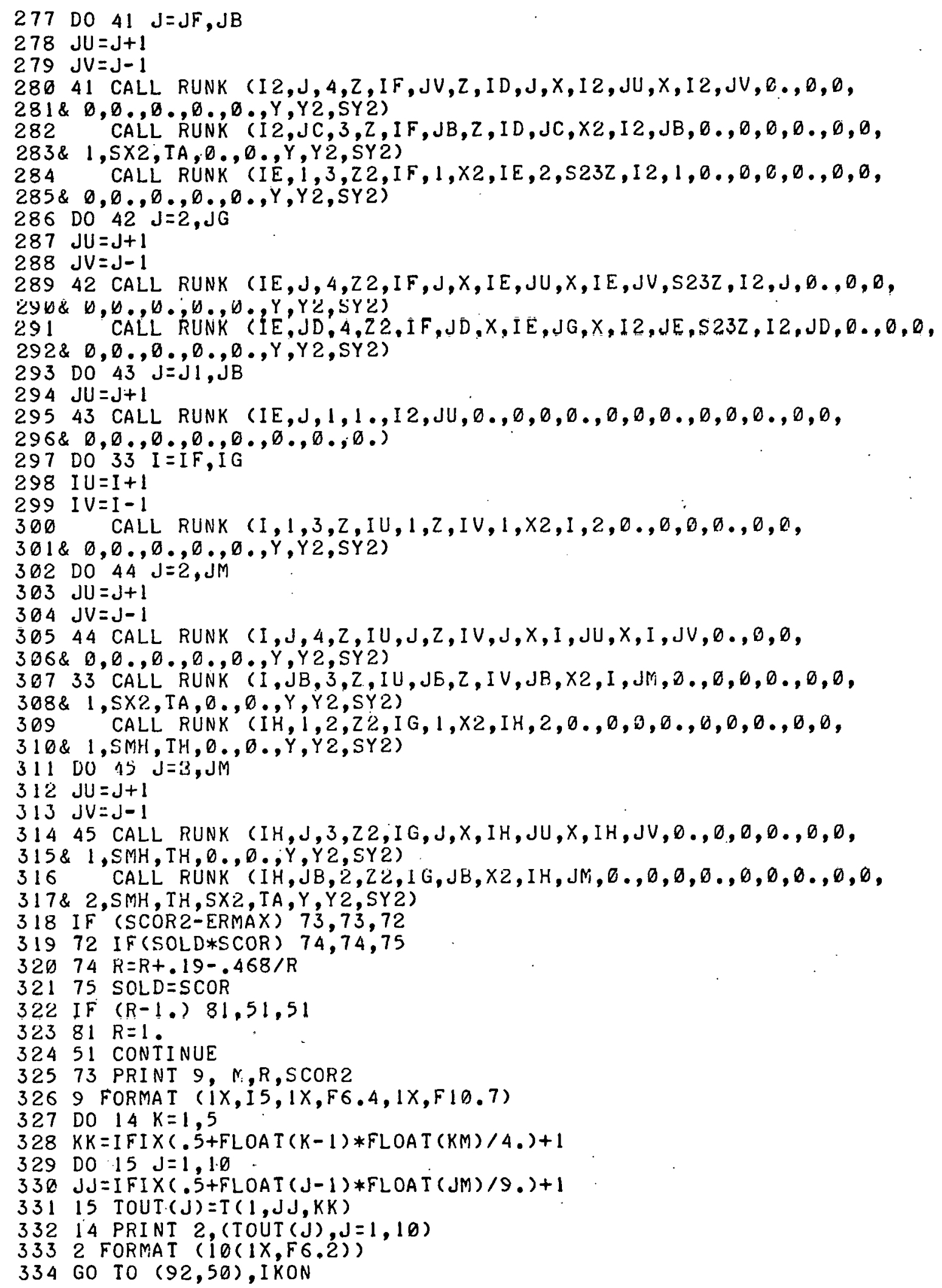




\section{APPENDIX}

GDL 6

$\# 05$

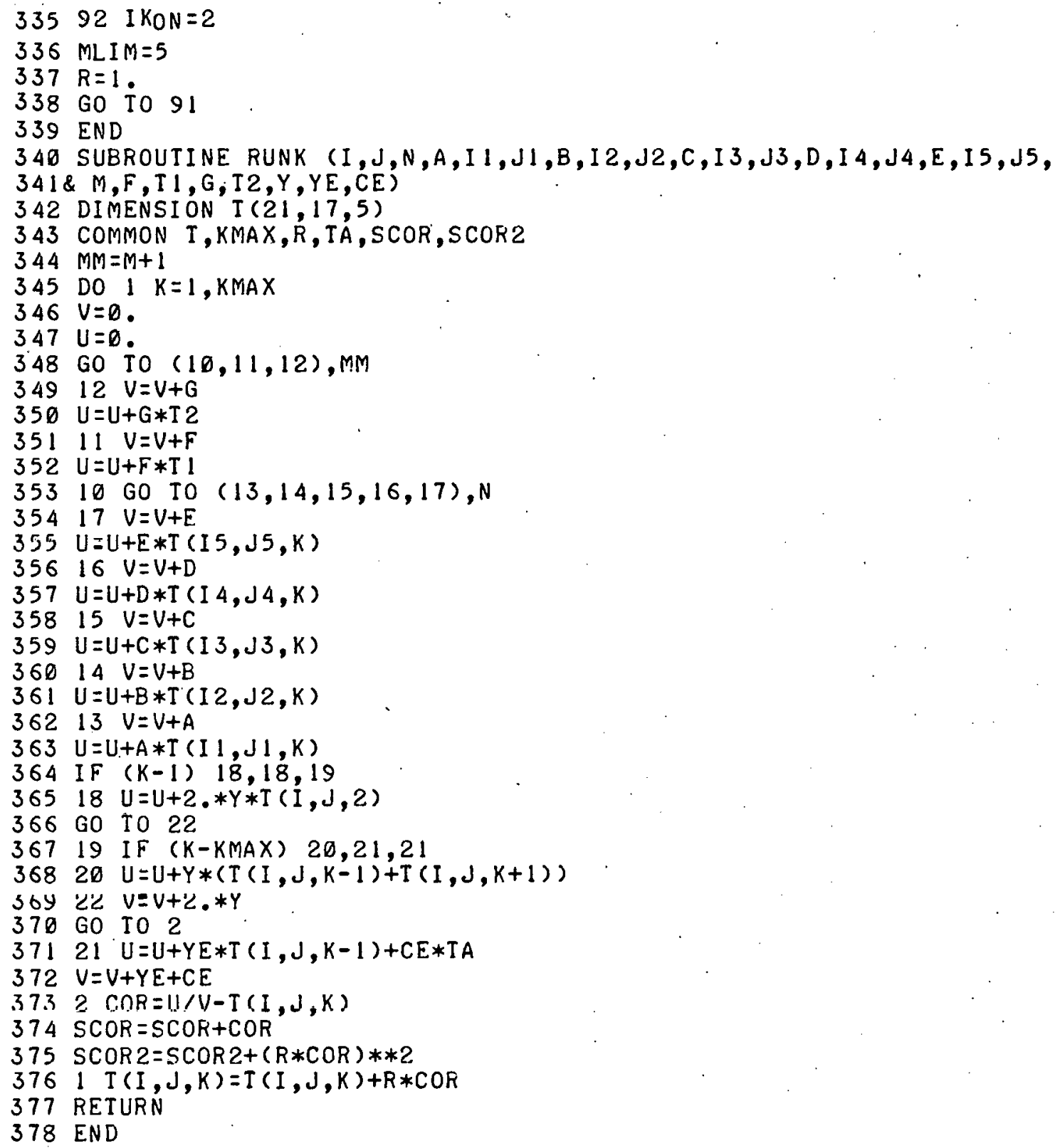

